\title{
Morphometric analysis of infraorbital foramen in Indian dry skulls
}

Rajani Singh

Department of Anatomy, CSM Medical University, Lucknow, UP, India

\begin{abstract}
We analyzed the variability in position, shape, size and incidence of the infraorbital foramen in Indian dry skulls as little literature is available on this foramen in Indians to prevent clinical complications during maxillofacial surgery and regional block anesthesia. Fifty-five Indian skulls from the Department of Anatomy CSM Medical University were examined. The 110 sides (left and right) of the skulls were analyzed by measuring the infraorbital foramina distances from infraorbital margin and the piriform aperture on both sides. The vertical and horizontal dimensions were also measured. All measurements were taken with a compass transferred to calipers and analyzed statistically. The mean distances between the infraorbital foramen and the infraorbital margin on the right and left side were $6.12 \mathrm{~mm}$ and $6.19 \mathrm{~mm}$, respectively. The mean distances between the infraorbital foramen and the piriform aperture were $15.31 \mathrm{~mm}$ and $15.80 \mathrm{~mm}$ on the right and left sides, respectively. The mean vertical dimensions on the right and left side were $3.39 \mathrm{~mm}$ and $3.75 \mathrm{~mm}$, respectively. The mean horizontal dimensions on the two sides were $3.19 \mathrm{~mm}$ and $3.52 \mathrm{~mm}$. These results provide detailed knowledge of the anatomical characteristics and clinical importance of the infraorbital foramina which are of paramount importance for surgeons when performing maxillofacial surgery and regional block anesthesia.
\end{abstract}

Key words: Skull, Infraorbital foramen, Maxillofacial surgery, Piriform aperture, Infraorbital margin

Received October 10, 2010; Revised January 8, 2011; Accepted January 19, 2011

\section{Introduction}

The infraorbital foramen is situated on the maxillary bone $1 \mathrm{~cm}$ below the infraorbital margin $[1,2]$ and the infraorbital nerve and vessels pass through it. These structures supply the lower eyelids, superior lip, ala of the nose and the premolar teeth.

A nerve block is essential during surgical procedures around the infraorbital foramen. Therefore the location of the infraorbital foramen assumes great importance. The analysis of important clinical, surgical and anesthetic aspect of the

\footnotetext{
Corresponding author:

Rajani Singh

Department of Anatomy, CSM Medical University, Lucknow 226003, UP, India

Tel: +91-94-53-193659, Fax: +91-522-2257539, E-mail:nani_sahayal@ rediffmail.com
}

Copyright (C) 2011. Anatomy \& Cell Biology infraorbital foramen in relation to the infraorbital margin may be summarized as follows [3]:

The location of the infraorbital foramen determines the orientation of an acupuncture point used in trigeminal neuralgia treatment [4]. The position of the infraorbital foramen helps to locate the infraorbital plexus region which we believe a risk zone during plastic surgery [5]. The location of this foramen determines morphometric variations from reference points to decrease the risk of orbital surgery [6]. The morphometry of this foramen plays an important role during regional block anesthesia techniques of the infraorbital nerve $[7,8]$. The precise location of the foramen facilitates risk free zygoma fracture surgery [9].

Thus knowledge of the infraorbital foramen location from reference points in this area provides important data for local anesthesia during rhinoplasty [10] and for the maxillofacial area during plastic surgery [11].

Modern surgical procedures [6], anesthesia [10] and

This is an Open Access article distributed under the terms of the Creative Commons Attribution Non-Commercial License (http://creativecommons.org/licenses/by-nc/3.0/) which permits unrestricted non-commercial use, distribution, and reproduction in any medium, provided the original work is properly cited. 
acupuncture require a more precise understanding of the surrounding anatomy [4].

This study was conducted to compare morphometric measurements of the infraorbital foramen in dry Indian skulls as there are no data on the location of the infraorbital foramen in the Indian population.

\section{Materials and Methods}

Fifty-five dry human adult skulls were examined at the Department of Anatomy, CSM Medical University. Skulls, with fractures in the piriform aperture, infraorbital foramen or at the infraorbital margin were excluded.

Various statistical analyses were conducted and the distances from the infraorbital foramen to the infraorbital margin and the piriform aperture were measured to study location pattern. Apart from this, measurements pertaining to shape and size of the foramen were also taken.

The reference point for that purpose was the center of the infraorbital foramen. Thus all measurements started from the infraorbital foramen to various land marks such as the infraorbital margin and piriform aperture.

The distances from the center of the infraorbital foramen to the infraorbital margin parallel to the sagittal plane which passes through the center of the infraorbital foramen, were measured. Another distance from this foramen to the piriform aperture along the transverse plane that passes through the center of the infraorbital foramen was taken as detailed in Fig. 1.

Vertical and horizontal dimensions of the foramina were also taken with double tipped compass. The compass opening was transferred to calipers to measure the distances. Range, mean, mode, median, and standard deviation were computed and analyzed statistically. Correlations were determined by
Pearson's correlation coefficient.

\section{Results}

A single infraorbital foramen was present bilaterally in all 55 observed skulls. The mean, mode, median, standard deviation and range derived from data pertaining to the distances between the infraorbital foramen-infraorbital margin, infraorbital foramen-piriform aperture and vertical as well as horizontal diameters of the infraorbital foramen are presented in Table 1.

The correlation of distances between the infraorbital foramen-infraorbital margin and the infraorbital foramenpiriform aperture on two sides of the skull was significant $(P<0.01)$ (Table 2). The percentage of horizontally and vertically oval shapes as well as circular shapes of the

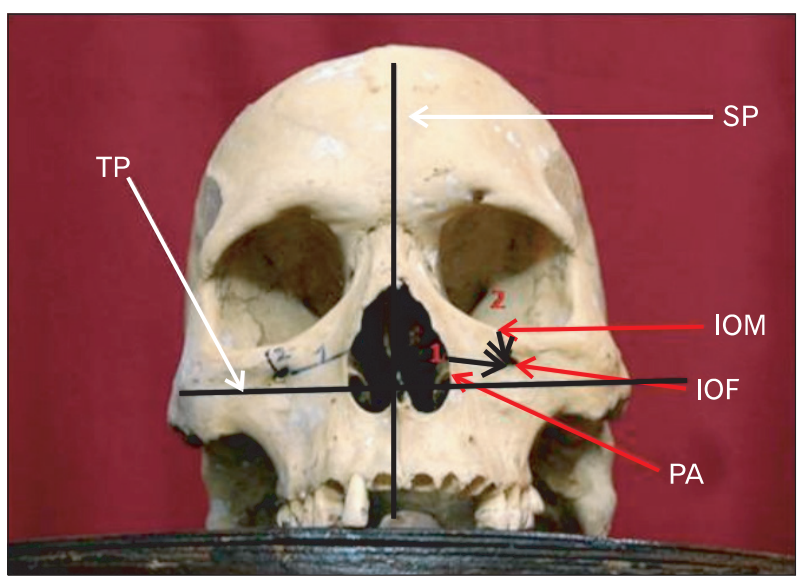

Fig. 1. Arrow 1 represents the distance between infraorbital foramen and the piriform aperture along the sagittal plane. Arrow 2 represents the distance between infraorbital foramen and infraorbital margin along transverse plane perpendicular to the sagittal plane. IOF, infraorbital foramen; IOM, infraorbital margin; PA, piriform aperture; SP, sagittal plane; TP, transverse plane.

Table 1. Statistical analysis of IOF regarding its location and shape

\begin{tabular}{|c|c|c|c|c|c|c|c|c|c|}
\hline \multirow{2}{*}{$\begin{array}{l}\text { Distances of IOF from land } \\
\text { marks and diameters }\end{array}$} & \multicolumn{3}{|c|}{ Mean \pm SD } & \multicolumn{2}{|c|}{ Median } & \multicolumn{2}{|c|}{ Mode } & \multicolumn{2}{|c|}{ Range } \\
\hline & Right & Left & Total & Right & Left & Right & Left & Right & Left \\
\hline IOM & $6.12 \pm 1.79$ & $6.19 \pm 1.81$ & $6.16 \pm 1.8$ & 6 & 6 & 5 & 5 & $3-11$ & $2-11$ \\
\hline PA & $15.31 \pm 1.77$ & $15.80 \pm 2.86$ & $15.56 \pm 2.6$ & 15 & 16 & 15 & 17 & $6.5-21$ & $6.5-20.5$ \\
\hline VD & $3.39 \pm 0.96$ & $3.75 \pm 1.07$ & $3.57 \pm 1.0$ & 3.5 & 4 & 4 & 4 & $1-5$ & $2-6$ \\
\hline $\mathrm{HD}$ & $3.19 \pm 1.18$ & $3.52 \pm 1.35$ & $3.35 \pm 1.3$ & 3 & 3.5 & 3 & 2 & $1-6$ & $1.5-6$ \\
\hline
\end{tabular}

All numbers are presented as mm. IOF, infraorbital foramen; SD, standard deviation; IOM, infraorbital margin; PA, piriform aperture; VD, vertical diameter; HD, horizontal diameter. 
infraorbital foramen on the left side were 30.09\%, 45.45\%, and $23.6 \%$, respectively whereas incidences of horizontally and vertically oval shapes as well as circular shapes on the right side were $25.4 \%, 40 \%$, and $34.5 \%$, respectively. Considering 110 sides ( 55 skulls both sides), the incidence of a horizontally oval type foramen was $28.1 \%$, vertically oval was $42.7 \%$ and circular type was $29 \%$ (Table 3 ).

The skew values in relation to the infraorbital forameninfraorbital margin were 2 and 3 whereas the skew values in relation to the infraorbital foramen-piriform aperture were 20 and 21.

\section{Discussion}

The infraorbital nerve and vessels pass through the infraorbital foramen therefore, knowledge of its location is very essential to surgeons and anesthetists for various surgical procedures in the Indian population in which data on this foramen are very scanty.

The distances between the infraorbital foramen and the midpoint of the infraorbital margin vary from 4 to $12 \mathrm{~mm}$ in

Table 2. Correlations of IOM and PA on right and left side of skull

\begin{tabular}{lllclc}
\hline & & IOML & $\begin{array}{c}\text { Piriform } \\
\text { AL }\end{array}$ & IOMR & $\begin{array}{c}\text { Piriform } \\
\text { AR }\end{array}$ \\
\hline IOML & $\begin{array}{l}\text { Pearson } \\
\text { correlation }\end{array}$ & 1 & $0.508^{*}$ & $0.767^{*}$ & 0.144 \\
& Sig. (2-tailed) & & 0 & 0 & 0.293 \\
& No. & 55 & 55 & 55 & 55 \\
\hline \multirow{2}{*}{ Piriform AL } & $\begin{array}{l}\text { Pearson } \\
\text { correlation }\end{array}$ & $0.508^{*}$ & 1 & $0.371^{*}$ & $0.556^{*}$ \\
& $\begin{array}{l}\text { Sig. (2-tailed) } \\
\text { IOMR }\end{array}$ & 0 & & 0.005 & 0 \\
& No. & 55 & 55 & 55 & 55 \\
& $\begin{array}{l}\text { Pearson } \\
\text { correlation }\end{array}$ & $0.767^{*}$ & $0.371^{*}$ & 1 & 0.228 \\
& Sig. (2-tailed) & 0 & 0.005 & & 0.094 \\
& No. & 55 & 55 & 55 & 55 \\
\hline Piriform AR & $\begin{array}{l}\text { Pearson } \\
\text { correlation }\end{array}$ & 0.144 & $0.556^{*}$ & 0.228 & 1 \\
& Sig. (2-tailed) & 0.293 & 0 & 0.094 & \\
\hline & No. & 55 & 55 & 55 & 55 \\
\hline
\end{tabular}

${ }^{*}$ Correlation is significant at the 0.01 level (2-tailed). IOML, infraorbital margin distance on left side from infraorbital foramen; Piriform AR, distace of piriform aperture from infraorbital foramen on right side; IOMR, infraorbital margin distance on right side from infraorbital foramen; Piriform AL, distance of piriform aperture from infraorbital foramen on left side; No., total skull used. several studies $[6,11,12]$ but the same distance ranged from 2 to $11.5 \mathrm{~mm}$ in current study. The range of these distances was wider on lower side among Indians which is an alert to surgeons treating Indians anywhere in the world.

The mean distance between the infraorbital foramen and the infraorbital margin was $6.16 \mathrm{~mm}$ which was very close to that of $6.10 \mathrm{~mm}$ by Hindy and Abdel-Raouf [12] as described in Table 4 [3, 4, 6, 7, 11-14].

The mean distance of the infraorbital foramen from the piriform aperture was $15.56 \mathrm{~mm}$ which was close to 14.70 $\mathrm{mm}$ reported by Kazkayasi et al. [14] as described in Table 5 [3, $12,14]$.

The range provides an indication of the location of the infraorbital foramen depending upon sample space and the dispersion of values. The mean distance is indicative of the infraorbital foramen location. The standard deviation provides variability in the position of the foramen around mean position. This is very vital information for rapidly locating this foramen during surgical procedures.

The mode of the distances of the infraorbital foramen and the infraorbital margin on both sides of the skull was 5 -indicating that this distance is $5 \mathrm{~mm}$ in most of Indian

Table 3. Shape of infraorbital foramen

\begin{tabular}{cccc}
\hline & Vertically oval (\%) & Horizontally oval (\%) & Circular (\%) \\
\hline Rt & 40 & 25.4 & 34.5 \\
Lt & 45.45 & 30.09 & 23.6 \\
R+L & 42.7 & 28.1 & 29 \\
\hline
\end{tabular}

Rt, right side; Lt, left side; $\mathrm{R}+\mathrm{L}$, right and left side combined.

Table 4. Comparative mean distances between IOF and IOM

\begin{tabular}{lc}
\hline \multicolumn{1}{|c}{ References } & Diatances (mm) \\
\hline Hindy and Abdel-Raouf [12] & 6.10 \\
\hline Chung et al. [7] & 8.60 \\
\hline Esper et al. [4] & 6.80 \\
\hline Canan et al. [13] & 8.30 in females, 10.90 in males \\
\hline Aziz et al. [11] & 7.80 in females, 8.50 in males \\
\hline Kazkayasi et al. [14] & 6.19 \\
\hline Karakaş et al. [6] & 6.7 \\
\hline Macedo et al. [3] & 6.37 \\
\hline Present study & 6.16 \\
\hline
\end{tabular}

IOF, infraorbital foramen; IOM, infraorbital margin. 
Table 5. Comparative mean distances between IOF and PA

\begin{tabular}{lc}
\hline \multicolumn{1}{c}{ References } & Distances (mm) \\
\hline Hindy and Abdel-Raouf [12] & 17.23 \\
Kazkayasi et al. [14] & 14.70 \\
Macedo et al. [3] & 17.67 \\
Present study & 15.56 \\
\hline
\end{tabular}

IOF, infraorbital foramen; PA, piriform aperture.

population. Therefore, this distance should be considered when locating the infraorbital foramen during maxillofacial surgery. The mode of infraorbital foramen and piriform aperture distances on the left and right sides were 17 and 15 , respectively which provides the most frequent distances to be used when locating the infraorbital foramen precisely in relation to piriform aperture.

However surgeons should consider the skew values to prevent surgical complications in the head and neck region and the anesthetist should consider these values for anesthetic failures of nerve block. Skew values are very rare values but their incidences cannot be ruled out. Although the skew values of these distances in data set influence the mean making the analysis more subjective, the results of this analysis will be very useful to surgeons and anesthetist.

The incidence of a single foramen on either side in all skulls was in contrast to more than one foramen in $10 \%$ of adult cadavers [14].

The shape of the infraorbital foramen was oval in $71 \%$ of the skulls ( $28.2 \%$ horizontally and $42.8 \%$ vertically oval) as compared to $34 \%$ of skulls with an oval shape [14]. We detected 29\% circular but no semicircular shaped infraorbital foramen whereas $66 \%$ of infraorbital foramen were circular and semicircular [14]. Thus the incidence of an oval shaped infraorbital foramen was higher in present study than that observed by Kazkayasi et al. [14]. These aforementioned results regarding foramen shapes are indicative of different osteoblastic and osteoclastic activities after birth.

An analysis of infraorbital foramen location in males and females has been conducted separately $[11,13]$ as depicted in Table 4.

The results showed a large dispersion and variability in the various distances pertaining to the location of the infraorbital foramen because we analyzed skulls from various geographical areas, individual's precision in measurements and varying osteoblastic and osteoclastic activity in different individuals. The various mean distances constrained by standard deviation as elaborated in table/s determine the exact position of infraorbital foramen in Indian population and may be first hand vital information to concerned clinicians to avoid complications during surgical procedures and nerve block. The skew values found in present study alert the surgeons to avoid anesthetic failures and other procedures involving infraorbital foramen. Statistically, there was no significant difference on left and right sides in relation to distances between infraorbital foramen and infraorbital margin along with piriform aperture. There was significant correlation on two sides of skull in relation to distances of infraorbital foramen to infraorbital margin and piriform aperture.

\section{References}

1. Gardner E, Gray DJ, O'Hailly R. Anatomia: estudo regional do corpo humano. 4th ed. Riode Janeiro: Guanabra Koogan; 1988.

2. Williams PL, Warwick R, Dyson M, Bannister LH. Gray's anatomy. 37th ed. New York: Churchill Livingstone; 1989.

3. Macedo VC, Cabrini RR, Faig-Leite H. Infraorbital foramen location in dry human skulls. Braz J Morphol Sci 2009;26:35-8.

4. Esper RS, Yara J, Yamamura Y, Cricenti SV. Relações anatômicas do ponto de acupuntura E-2 (Sibai) localizado no forame infraorbital. Rev Paul Acupunt 1998;4:19-21.

5. Hwang K, Han JY, Battuvshin D, Kim DJ, Chung IH. Communication of infraorbital nerve and facial nerve: anatomic and histologic study. J Craniofac Surg 2004;15:88-91.

6. Karakaş P, Bozkir MG, Oguz O. Morphometric measurements from various reference points in the orbit of male Caucasians. Surg Radiol Anat 2003;24:358-62.

7. Chung MS, Kim HJ, Kang HS, Chung IH. Locational relationship of the supraorbital notch or foramen and infraorbital and mental foramina in Koreans. Acta Anat (Basel) 1995;154:162-6.

8. Radwan IA, Saito S, Goto F. High-concentration tetracaine for the management of trigeminal neuralgia: quantitative assessment of sensory function after peripheral nerve block. Clin J Pain 2001;17:323-6.

9. Du Tolt DF, Nortjé C. The maxillae: integrated and applied anatomy relevant to dentistry. SADJ 2003;58:325-30.

10. Zide BM, Swift R. How to block and tackle the face. Plast Reconstr Surg 1998;101:840-51.

11. Aziz SR, Marchena JM, Puran A. Anatomic characteristics of the infraorbital foramen: a cadaver study. J Oral Maxillofac Surg 2000;58:992-6.

12. Hindy AM, Abdel-Raouf F. A study of infraorbital foramen, canal and nerve in adult Egyptians. Egypt Dent J 1993;39:57380 .

13. Canan S, Asim OM, Okan B, Ozek C, Alper M. Anatomic 
variations of the infraorbital foramen. Ann Plast Surg 1999;43:613-7.

14. Kazkayasi M, Ergin A, Ersoy M, Bengi O, Tekdemir I, Elhan A.
Certain anatomical relations and the precise morphometry of the infraorbital foramen. Canal and groove: an anatomical and cephalometric study. Laryngoscope 2001;111(4 Pt 1):609-14. 